ARTICLE OPEN

\title{
Large piezoelectric response in a family of metal-free perovskite ferroelectric compounds from first-principles \\ calculations
}

\author{
Hui Wang ${ }^{1}$, Huihui Liu ${ }^{1}$, Zeyu Zhang ${ }^{1}$, Zihan Liu ${ }^{1}$, Zhenlong Lv ${ }^{1}$, Tongwei Li ${ }^{1}$, Weiwei Ju ${ }^{1}$, Haisheng Li ${ }^{1}$, Xiaowu Cai ${ }^{2}$ and Han Han ${ }^{3}$
}

Metal-free organic perovskite ferroelectric materials have been shown recently to have a number of attractive properties, including high spontaneous polarization and piezoelectric coefficients. In particular, slow evaporation of solutions containing organic amines, inorganic ammoniums, and dilute hydrohalogen acid has been shown to produce several attractive materials in the $\mathrm{MDABCO}^{-\mathrm{NH}_{4}-}$ $\mathrm{I}_{3}$ family (MDABCO is $\mathrm{N}$-methyl-N'-diazabicyclo[2,2,2] octonium). In the present work, we study by first-principles calculations the origin of polarizaiton, electronic density of state, piezoelectric response, and elastic properties of $\mathrm{MDABCO}-\mathrm{NH} \mathrm{H}_{4}-\mathrm{X}_{3}(\mathrm{X}=\mathrm{Cl}, \mathrm{Br}, \mathrm{I})$. We find that the dipole moments of the MDABCO and $\mathrm{NH}_{4}$ groups are negligible, and the large spontaneous polarization of MDABCO$\mathrm{NH}_{4}-\mathrm{I}_{3}$ mainly results from $\mathrm{MDABCO}$ and $\mathrm{NH}_{4}$ being off-center relative to I ions. Although the piezoelectric response of organic materials is usually very weak, we observe large piezoelectric strain components, $d_{x 4}$ and $d_{x 5}$; the calculated $d_{x 5}$ is $119 \mathrm{pC} / \mathrm{N}$ for MDABCO- $\mathrm{NH}_{4}-\mathrm{Cl}_{3}, 248 \mathrm{pC} / \mathrm{N}$ for MDABCO- $\mathrm{NH}_{4}-\mathrm{Br}_{3}$ and $178 \mathrm{pC} / \mathrm{N}$ for MDABCO- $\mathrm{NH}_{4}-\mathrm{I}_{3}$. The large value of $d_{x 5}$ is found to be closely related with the large value of elastic compliance tensor, $s_{44}$. These results show that MDABCO-NH ${ }_{4}-\mathrm{X}_{3}$ metal-free organic perovskites have large piezoelectric response with soft elastic properties.

npj Computational Materials (2019)5:17; https://doi.org/10.1038/s41524-019-0157-4

\section{INTRODUCTION}

The perovskite structures have been dubbed a "chameleon" due to their rich diversity of chemical compositions and physical properties. $^{1-3}$ Searching for large piezoelectric perovskites has been the aspiration of science and engineering studies. ${ }^{4}$ Compared with inorganic perovskite, organic materials possess many advantages. For example, organic crystals can be synthesized at relatively low temperature. ${ }^{5}$ The easy reorientation inorganic cations make them promising candidates for order-disorder ferroelectrics. ${ }^{6,7}$ By replacing $\mathrm{Pb}$ and other toxic ions with inorganic cations, they can be designed to toxic-metalfree materials. Therefore, organic materials have become an attractive topic not only due to the remarkable structural variability and highly tunable properties, but also due to their potential applications in light sources, photovoltaics, and electronics. $^{8}$

Recently, a breakthrough of piezoelectric material was reported by Yu-Meng You, Ren-Gen Xiong, and colleagues. ${ }^{9}$ Based on molecular design strategy and elaborate organic cation selection, they successfully synthesized a family of metal-free organic perovskite ferroelectrics. This family contains 23 new compounds, in which 21 compounds have cubic perovskite structure and the other two have hexagonal perovskite structure. Among these cubic perovskite compounds, 14 compounds show paraelectricferroelectric transition and their Curie temperatures range from 355 to $493 \mathrm{~K}$. This means all of them are ferroelectric at room temperature. The general formula of this family is $A\left(\mathrm{NH}_{4}\right) \mathrm{X}_{3}$, in which $A$ is a divalent organic cation and $X$ is halogen anion.
Despite their diversity, compounds of this family were obtained easily by a simple strategy: slow evaporation of solution containing organic ammines, inorganic ammoniums, and dilute hydrohalogen acid. Not only the facile synthesis method but also their desirable properties make them are possible for application in flexible devices.

Among this metal-free organic perovskite family, MDABCO-NH ${ }_{4}^{-}$ $I_{3}$ (MDABCO is $\mathrm{N}$-methyl- $\mathrm{N}^{\prime}$-diazabicyclo[2,2,2]octonium) is an outstanding one. Its ferroelectric Curie temperature $\left(T_{0}\right)$ is $448 \mathrm{~K}$, spontaneous polarization $\left(P_{\mathrm{s}}\right)$ is $22 \mu \mathrm{C} / \mathrm{cm}^{2}$ and piezoelectric coefficient $d_{33}$ (along [ $\left[\begin{array}{lll}1 & 1 & 1\end{array}\right]$ direction) is about $14 \mathrm{pC} / \mathrm{N}^{9}$. Furthermore, second-harmonic generation response and dielectric permittivity were also measured as a function of temperature. Although a detailed investigation of MDABCO- $\mathrm{NH}_{4} \mathrm{I}_{3}$ was made in experiment, some important physical properties were not reported. For example, except for the longitude piezoelectric stress coefficient $d_{33}$, other elements of piezoelectric stress tensor were not measured in experiment. Furthermore, the elastic tensor and piezoelectric strain tensor were not reported, too.

\section{RESULTS AND DISCUSSION}

In order to elucidate the piezoelectric and elastic properties of MDABCO- $\mathrm{NH}_{4}-\mathrm{I}_{3}$, we performed the density-functional theory (DFT) calculation using Perdew-Burke-Ernzerhof $(\mathrm{PBE})^{10}$ and PBE-D3 ${ }^{11}$ methods as implemented in the Vienna ab initio simulation package (VASP). ${ }^{12-14}$

The primitive and conventional unit cells of MDABCO-NH $\mathrm{NH}_{4} \mathrm{I}_{3}$ in ferroelectric phase are depicted in Fig. 1. Herein, the MDABCO-

\footnotetext{
${ }^{1}$ School of Physics and Engineering, Henan University of Science and Technology, 471003 Luoyang, China; ${ }^{2}$ Institute of Microelectronics of Chinese Academy of Sciences, 100029 Beijing, China and ${ }^{3}$ School of Physical Science and Technology, Shanghai Tech University, 201210 Shanghai, China

Correspondence: Hui Wang (nkxirainbow@gmail.com) or Han Han (hanhanfudan@gmail.com)
}

Received: 31 August 2018 Accepted: 22 January 2019

Published online: 06 February 2019 


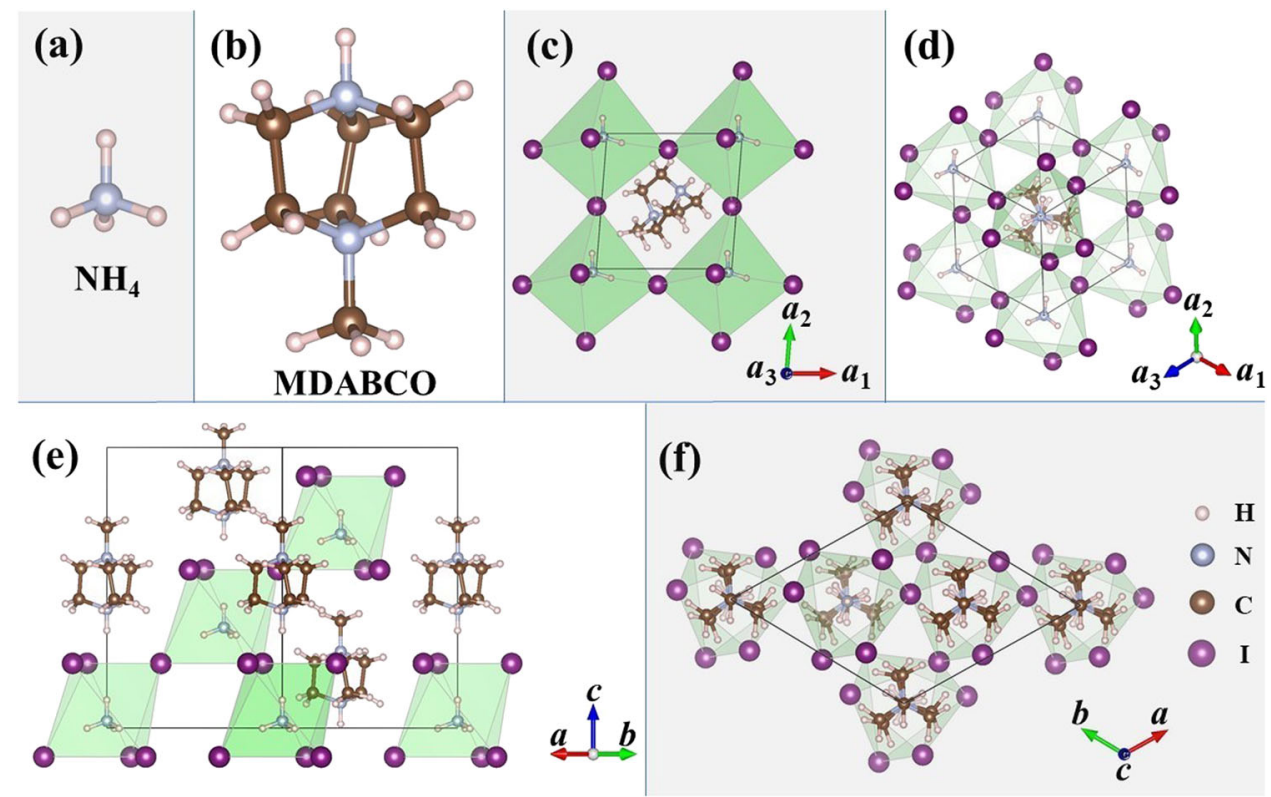

Fig. 1 The ferroelectric structure of MDABCO- $\mathrm{NH}_{4}-\mathrm{I}_{3}$. $\mathbf{a}$ and $\mathbf{b}$ are $\mathrm{NH}_{4}$ and $\mathrm{MDABCO}$ groups, $\mathbf{c}$ and $\mathbf{d}$ are the primitive unit cell viewed along $[0$

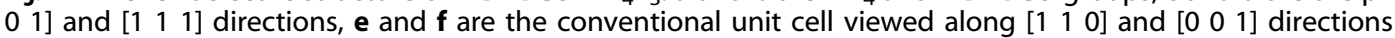

$\mathrm{NH}_{4} \mathrm{I}_{3}$ crystal is composed of three building blocks: $\mathrm{NH}_{4}, \mathrm{MDABCO}$, and $\mathrm{I}_{6}$ octahedron. The $\mathrm{NH}_{4}$ locates in the middle of $\mathrm{I}_{6}$ octahedron, which shares corners with its six neighboring octahedra to form a three-dimensional (3D) network. The MDABCO locates in the middle of a cage defined by 12 iodine ions. It has a trigonal structure with space group $R 3$. The three-fold axis passes through the two nitrogen atoms of MDABCO and the spontaneous polarization direction is parallel to this axis (z-axis). Similarly with $\mathrm{K}_{3} \mathrm{BO}_{10} \mathrm{Cl}^{15-17}$ and trimethylchloromethyl ammonium trichloromanganese, ${ }^{5}$ it is the ordered cation MDABCO that breaks the inversion symmetry and permits the occurrence of ferroelectric, piezoelectricity, second-harmonic generation, and other interesting phenomena. When temperature increases above $448 \mathrm{~K}$, it turns to a cubic paraelectric phase. ${ }^{9}$ Besides MDABCO-NH ${ }_{4}-\mathrm{I}_{3}, \mathrm{MDABCO}-$ $\mathrm{NH}_{4}-\mathrm{Br}_{3}$ is also successfully synthesized with similar method. ${ }^{9}$ It has a similar structure with MDABCO-NH${ }_{4}^{-I_{3}}$ and exhibits paraelectric-ferroelectric transition at $390 \mathrm{~K}$.

So as to calculate the properties of these newly synthesized crystal, we relaxed their atomic positions and lattice parameters first. For MDABCO-NH $\mathrm{N}_{4} \mathrm{I}_{3}$ and $\mathrm{MDABCO}-\mathrm{NH}_{4}-\mathrm{Br}_{3}$, we used the experimental data for their initial structures. Then, lattice parameters and atomic positions are relaxed without any symmetry constraint until calculated stresses and forces are less than the threshold. As MDABCO- $\mathrm{NH}_{4}-\mathrm{Cl}_{3}$ is not synthesized in experiment, we substitute the $\mathrm{Br}$ in MDABCO-NH $\mathrm{N}_{4}-\mathrm{Br}_{3}$ to $\mathrm{Cl}$ as its initial structure. ${ }^{18,19}$ Then, we relaxed lattice parameters and atomic positions of MDABCO-NH4- $\mathrm{Cl}_{3}$ until they meet the threshold. So as to verify the calculated structure are stable, we calculated their zone center phonon frequencies and do not find unstable mode. Moreover, they all satisfy the mechanical stability criteria, namely, that the stiffness tensor is positive-definite. ${ }^{20}$ The calculated lattice parameters of primitive unit cell are listed in Table 1 and are compared with available experimental data.

Because MDABCO- $\mathrm{NH}_{4}-\mathrm{X}_{3}$ are molecular materials, we use the DFT-D3 method to take the van de Waals interaction into consideration. ${ }^{9}$ Unfortunately, PBE + D3 does not give better result compared with $\mathrm{PBE}$. As far as the angle is concerned, PBE functional is slightly better than $\mathrm{PBE}+\mathrm{D} 3$. However, when it comes to the lattice length, PBE functional performs much better than $\mathrm{PBE}+\mathrm{D} 3$. The PBE result overestimates the lattice parameter of $\mathrm{MDABCO}-\mathrm{NH}_{4}-\mathrm{I}_{3} 1.5 \%$, and $\mathrm{PBE}+\mathrm{D} 3$ underestimates $1.9 \%$. For
Table 1. Experimental and calculated lattice parameters of ferroelectric MDABCO-NH${ }_{4}-\mathrm{X}_{3}$

\begin{tabular}{|c|c|c|c|}
\hline Material & & $a(\AA)$ & $a\left(^{\circ}\right)$ \\
\hline \multirow[t]{2}{*}{ MDABCO- $\mathrm{NH}_{4}-\mathrm{Cl}_{3}$} & PBE & 6.84 & 84.30 \\
\hline & $\mathrm{PBE}+\mathrm{D} 3$ & 6.64 & 84.22 \\
\hline \multirow[t]{3}{*}{ MDABCO- $\mathrm{NH}_{4}-\mathrm{Br}_{3}$} & Exp. & 7.1947 & 84.867 \\
\hline & PBE & $7.04(-2.1 \%)$ & $84.59(-0.3 \%)$ \\
\hline & $\mathrm{PBE}+\mathrm{D} 3$ & $6.82(-5.2 \%)$ & $84.63(-0.3 \%)$ \\
\hline \multirow[t]{3}{*}{ MDABCO-NH ${ }_{4}^{-} \mathrm{I}_{3}$} & Exp. & 7.259 & 84.767 \\
\hline & PBE & 7.37 (1.5\%) & $85.11(0.4 \%)$ \\
\hline & $\mathrm{PBE}+\mathrm{D} 3$ & $7.12(-1.9 \%)$ & 85.16 (0.5\%) \\
\hline
\end{tabular}

MDABCO- $\mathrm{NH}_{4}-\mathrm{Br}_{3}, \mathrm{PBE}$ underestimates lattice parameter 2.1\%, while PBE + D3 underestimates it as large as 5.2\%. This means PBE is more suitable than PBE $+\mathrm{D} 3$ in $\mathrm{MDABCO}-\mathrm{NH}_{4}-\mathrm{X}_{3}$ calculation. The poor performance of PBE-D3 is due to the hydrogen bond in MDABCO-NH ${ }_{4} \mathrm{X}_{3}$. The total energy of DFT-D3 is $E_{\mathrm{KS}-\mathrm{DFT}}-E_{\text {disp. }}{ }^{11}$ The first term $E_{\mathrm{KS}-\mathrm{DFT}}$ is the usual self-consistent KS energy and the second term $E_{\text {disp }}$ is the dispersion correction. This correction is a sum of two- and three-body energies, related with bond length, bond angle and etc. However, it has no relationship with the electronic band structure. Therefore, the developers of DFT-D3 says "the method is of molecular mechanics type in the sense that it is very fast and only geometric information is employed". ${ }^{11}$ It is pointed in refs. ${ }^{21-24}$ that the long-range part of the exchange contribution is overestimated in PBE. This overestimation compensates the missing vdW interaction to some extent. Consequently, directly adding additional dispersion correction to PBE would lead to an unphysical 'double-counting" effect. ${ }^{22}$ As shown in ref. ${ }^{11}$, this unphysical effect in hydrogen bond is severe and results into the poor performance of PBE-D3. Therefore, we use the atom position and lattice parameters of PBE and calculate other properties with PBE functional as well.

So as to investigate the origin of large spontaneous polarization $\left(22 \mu \mathrm{C} / \mathrm{cm}^{2}\right)$ of MDABCO- $\mathrm{NH}_{4}-\mathrm{I}_{3}$, we calculate its Born effective 
(a)

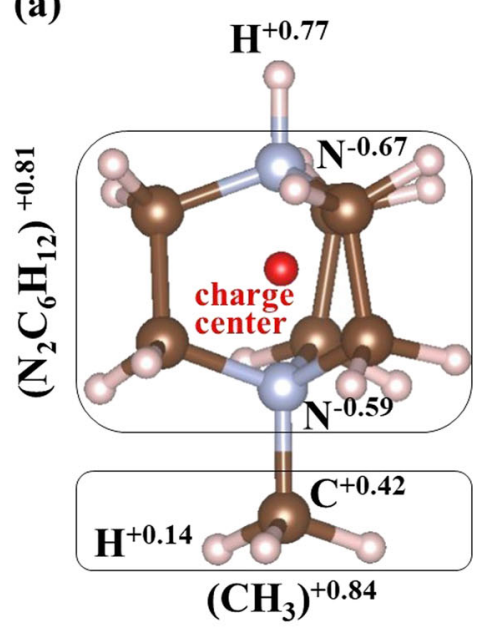

(b)

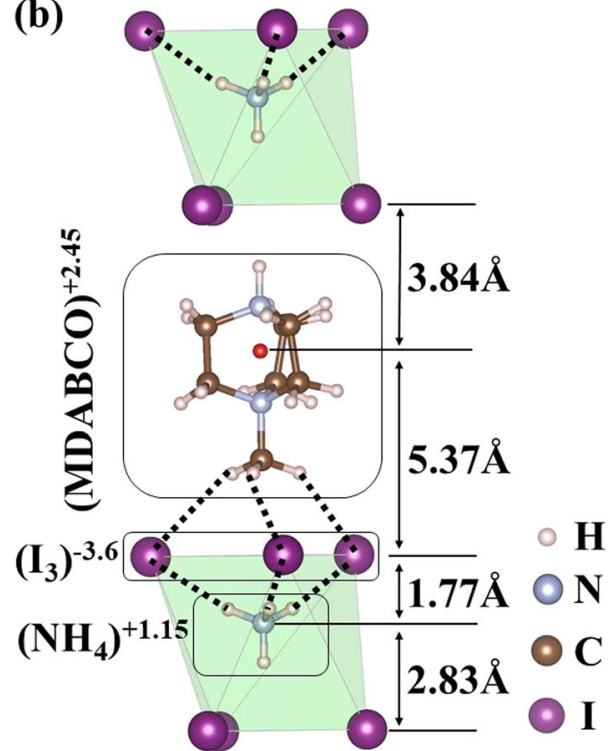

Fig. 2 The calculated structure and Born effective charges of MDABCO-NH$H_{4} \mathrm{I}_{3}$. $\mathbf{a}$ The Born effective charges of MDABCO. $\mathbf{b}$ The Born effective charges and relative positions of MDABCO, $\mathrm{NH}_{4}$, and $\mathrm{I}_{3}$ groups. The dashed lines show hydrogen bonds between $\mathrm{H}^{+}$and $\mathrm{I}^{-}$

charge (BEC). BEC is a second-order tensor and the component along the dipole direction is related with ferroelectric polarization. The calculated BEC components along the dipole direction are marked in Fig. 2.

As shown in Fig. 2a, MDABCO can be divide into three parts. The top hydrogen, the bottom $\mathrm{CH}_{3}$ and the middle $\mathrm{N}_{2} \mathrm{C}_{6} \mathrm{H}_{12}$ part. Their BECs are $+0.84,+0.81$, and +0.77 , respectively. For MDABCO, all $C$ and $\mathrm{H}$ show positive values, only $\mathrm{N}$ shows negative values. We calculate the positive and negative charge centers of MDABCO, and find the distance between the two centers is as small as $0.009 \AA$. They are almost overlap with each other. Therefore, the dipole moment of the MDABCO group is negligible. The total charge of MDABCO is +2.45 and the total charge center is marked as a red point in Fig. 2. The positive and negative charge centers of $\mathrm{NH}_{4}$ are almost overlap with each other, too. Therefore, the dipole moment of the $\mathrm{NH}_{4}$ group is negligible. The total charge of $\mathrm{NH}_{4}$ is +1.15 , centered at the $\mathrm{N}$ position. The charge of $\mathrm{I}$ is -1.2 , similar to its formal charge -1 . The relative positions of MDABCO, $\mathrm{NH}_{4}$, and $\mathrm{I}_{3}$ along the dipole moment direction are depicted in Fig. $2 \mathrm{~b}$. It is clear that the charge center of MDABCO (A-site of perovskite) shifts upward with the distance $d_{\mathrm{A}}=(5.37-3.84) / 2=0.765 \AA$ relative to the center of its nearest neighboring six $\mathrm{I}^{-}$ions. At the same time, the charge center of $\mathrm{NH}_{4}$ (B-site of perovskite) shifts upward, too, with the distance $d_{\mathrm{B}}=(2.83-1.77) / 2=0.53 \AA$ relative to the center of $\mathrm{I}_{6}$ octahedron. As a comparison, the A-site and B-site displacements of rhombohedral $\mathrm{BaTiO}_{3}$ are 0.10 and $0.19 \AA$, respectively. They are much smaller than the corresponding off-center distance of $\mathrm{MDABCO}-\mathrm{NH}_{4}-\mathrm{I}_{3}$. Furthermore, $d_{\mathrm{A}}$ is larger than $d_{\mathrm{B}}$ for MDABCO-NH $\mathrm{PbTiO}_{3}$. This means that $\mathrm{MDABCO}-\mathrm{NH}_{4}-\mathrm{I}_{3}$ is an A-site driven ferroelectricity. On the contrary, $d_{\mathrm{A}}$ is smaller than $d_{\mathrm{B}}$ for $\mathrm{BaTiO}_{3}$, indicating a B-site driven ferroelectricity. Therefore, MDABCO- $\mathrm{NH}_{4}$ $\mathrm{I}_{3}$ is an A-site driven order-disorder ferroelectricity and its large polarization results from the large off-center distances of MDABCO and $\mathrm{NH}_{4}$ relative to $\mathrm{I}$.

As shown in the dashed lines of Fig. $2 b$, there are three hydrogen bonds between three hydrogens of $\mathrm{CH}_{3}$ and three $\mathrm{I}^{-}$ anions. And there are also three hydrogen bonds between three hydrogens of $\mathrm{NH}_{4}$ and its surrounding three $\mathrm{I}^{-}$anions. ${ }^{9}$ When MDABCO- $\mathrm{NH}_{4}-\mathrm{I}_{3}$ turns from ordered ferroelectric phase to disordered paraelectric phase, much energy is needed to break these six hydrogen bonds so as to make MDABCO and $\mathrm{NH}_{4}$ rotating freely. In paraelectric phase, the rotating MDABCO must overcome a barrier, in which the two $\mathrm{N}$ atoms of MDABCO lines along the $\left[\begin{array}{lll}1 & 1 & 0\end{array}\right]$ direction. So as to get the barrier value, we calculate the total energy of two configurations. In the first configuration, lattice parameters are set to the experimental value of paraelectric phase and I ions forms a cubic network. Then we fix the positions of I and set the two $\mathrm{N}$ and two $\mathrm{C}$ atoms of MDABCO along the $C_{3}$ axis to move only along the $\left[\begin{array}{lll}1 & 1 & 1\end{array}\right]$ direction. Other atoms can move freely. In the second configuration, lattice parameters and positions of I ions are the same as configuration one. Then the selected two $\mathrm{N}$ and two $\mathrm{C}$ atoms of MDABCO in the first configuration are set to move only along the $\left[\begin{array}{lll}1 & 1 & 0\end{array}\right]$ direction. Other atoms can move freely. The energy difference between the above two configurations is $\Delta E=0.156 \mathrm{eV}$ per primitive unit cell. As MDABCO is polyatomic molecules with six freedom (three translations and three rotations), the energy barrier corresponds to the temperature $T=\Delta E /\left(3 \times k_{\mathrm{B}}\right)=398 \mathrm{~K}$, which agrees with the experimental value $448 \mathrm{~K}$.

The structure evolution with $\mathrm{X}$ ions is presented in four parts. Firstly, the structure parameters inner MDABCO are shown in Fig. $3 a$. The bond lengths (solid red symbol) refer to the left axis, while the bond angles (open blue symbol) correspond to the right axis. With halogen changing from $\mathrm{Cl}$ to $\mathrm{l}$, the bond lengths change less than $0.01 \AA$ and the bond angles change $<0.2^{\circ}$ Therefore, the MDABCO group performs like a rigid body in MDABCO-NH $\mathrm{N}_{4}-\mathrm{X}_{3}$ crystals.

Secondly, the structure parameters between MDABCO and its surrounding $X$ ions are shown in Fig. 3b. There are two kinds of bond length between $\mathrm{H}$ and $\mathrm{X}$ ions. The first one is $d_{\mathrm{HX}} \mathrm{w}$ at the top of Fig. $3 \mathrm{~b}$ inset, while the second one is $d_{\mathrm{HX} s}$ at the bottom of Fig. $3 b$ inset (the subscript ' $w$ " and ' $s$ " represent 'relatively weak", and 'relatively strong"). The first bond length is larger than the second one, indicating the first hydrogen-halogen interaction is weaker than the second one. With the radius of $X$ ion increases from $\mathrm{Cl}$ to $\mathrm{I}$, the two hydrogen- $\mathrm{X}$ bond lengths increase. We also give the angles between $\mathrm{H}-\mathrm{X}$ bond and the $\mathrm{X}_{3}$ plane (inset of Fig. $3 b)$. With halogen changing from $\mathrm{Cl}$ to $\mathrm{l}$, the angle $\theta_{\mathrm{HX} 3}{ }_{\mathrm{w}}$ changes from $26.4^{\circ}$ to $31.1^{\circ}$, increasing $4.7^{\circ}$. However, the angle $\theta_{\mathrm{HX} 3 \mathrm{~s}}$ changes from $46.4^{\circ}$ to $44.4^{\circ}$, decreasing $2.2^{\circ}$. The opposite trends of $\theta_{\mathrm{HX} 3}{ }_{w}$ and $\theta_{\mathrm{H} 3_{3} \mathrm{~s}}$ originate from the A-site space changing of 


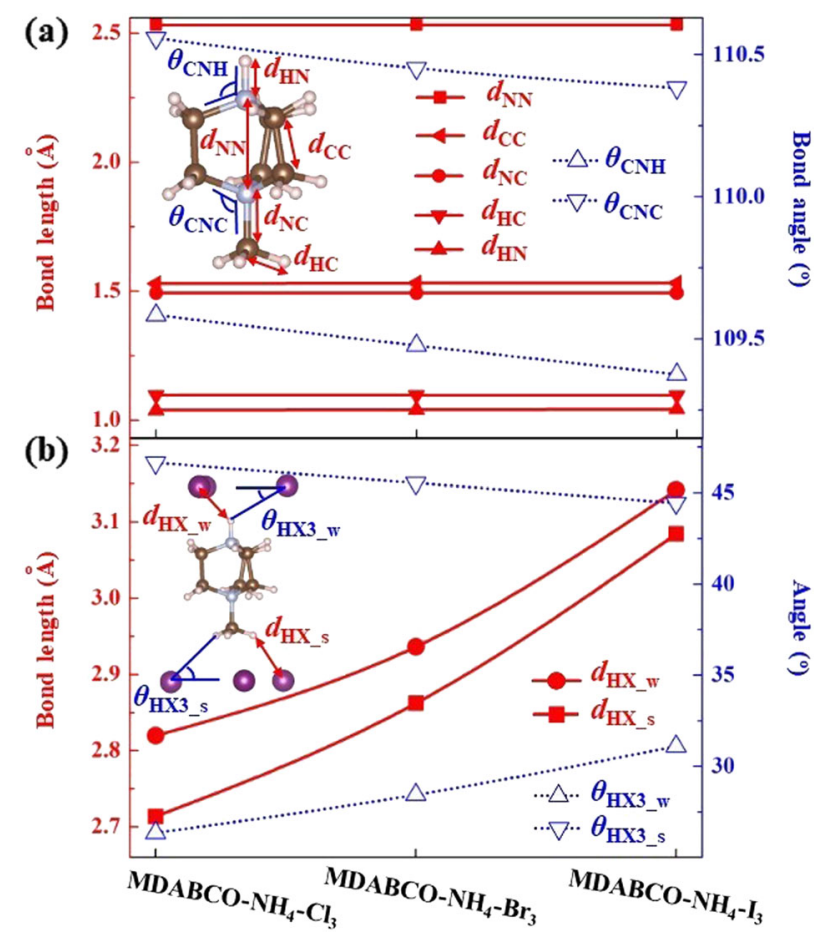

Fig. 3 The structure parameters $\mathbf{a}$ of inner MDABCO and $\mathbf{b}$ between MDABCO and its nearest neighboring $X$ ions. The solid red symbols refer to the left vertical axis, while the open blue ones refer to the right vertical axis. The inset structures depict the bond lengths and angles

perovskite. With ion changing from $\mathrm{Cl}^{-}$to $\mathrm{I}^{-}$, the lattice parameter of $\mathrm{MDABCO}-\mathrm{NH}_{4}-\mathrm{X}_{3}$ increases from 6.84 to $7.37 \AA$. Then, the corresponding A-site space of perovskite increases. In MDABCO$\mathrm{NH}_{4}-\mathrm{Cl}_{3}$, the MDABCO group is a little compressed as there is not enough room for it. When it comes to MDABCO- $\mathrm{NH}_{4}-\mathrm{I}_{3}$, there is spare room for MDABCO group. Because the hydrogen-halogen interaction at the bottom of Fig. $3 b$ inset is stronger than the top one, the bottom hydrogen approaches its neighboring I, decreasing $\theta_{\mathrm{HX}{ }_{3} \mathrm{~s}}$ while the top hydrogen leaves its neighboring I, increasing $\theta_{\mathrm{HX} 3}$ w.

Thirdly, we give the structure parameters inner $\mathrm{NH}_{4}$ in Fig. 4a. There are two $\mathrm{N}-\mathrm{H}$ bond length: $I_{\mathrm{NH} \_u p}$ and $I_{\mathrm{NH} \_d n}$. The first bond almost points to the neighboring $\mathrm{X}$ ion, while the second bond points to the middle of three $\mathrm{X}$ ions. Therefore, the first $\mathrm{N}-\mathrm{H}$ bond is enlarged by $X$ ions relative to the second one, resulting into $I_{\mathrm{NH} \text { up }}>I_{\mathrm{NH} \text { dn }}$. Because $\mathrm{NH}_{4}$ forms a tetrahedron, we calculate the Baur's distortion index $D$ with the following equation ${ }^{17,25}$ :

$D=\frac{1}{n} \sum_{i=1}^{n} \frac{\left|l_{i}-l_{\mathrm{av}}\right|}{l_{\mathrm{av}}}$

where $l_{i}$ is the distance from the central atom to the $i_{\text {th }}$ coordinating atom, and $l_{a v}$ is the average bond length. For a regular tetrahedron, the distortion index equals zero. For $\mathrm{NH}_{4}$ tetrahedron, the distortion index is very little, indicating that $\mathrm{NH}_{4}$ performs like a rigid body in MDABCO- $\mathrm{NH}_{4}-\mathrm{X}_{3}$.

Fourthly, we show the structure parameters between $\mathrm{NH}_{4}$ and its surrounding $\mathrm{X}$ ions in Fig. $4 \mathrm{~b}$. For a regular octahedron, $\mathrm{N}$ atom should locate at the center and $\boldsymbol{\varphi}_{\mathrm{XNX}}$ should be $180^{\circ}$. Actually, the angle $\boldsymbol{\varphi}_{\mathrm{XNX}}$ is about $157^{\circ}$, obviously deviating from the ideal value of $180^{\circ}$. With halogen changing from $\mathrm{Cl}$ to $\mathrm{I}, \boldsymbol{\varphi}_{\mathrm{XNX}}$ changes from $154.6^{\circ}$ to $158.7^{\circ}$, increasing $4.1^{\circ}$. Similarly with MDABCO, we also give the angles between $\mathrm{H}-\mathrm{X}$ bond and the $\mathrm{X}_{3}$ plane (inset of Fig. 4b). With halogen changing from $\mathrm{Cl}$ to I, the angle $\boldsymbol{\varphi}_{\mathrm{HX}{ }_{3} \mathrm{w}}$ changes from $36.0^{\circ}$ to $33.8^{\circ}$, decreasing $2.2^{\circ}$. However, the angle $\boldsymbol{\varphi}_{\mathrm{HX} 3 \mathrm{~s}}$

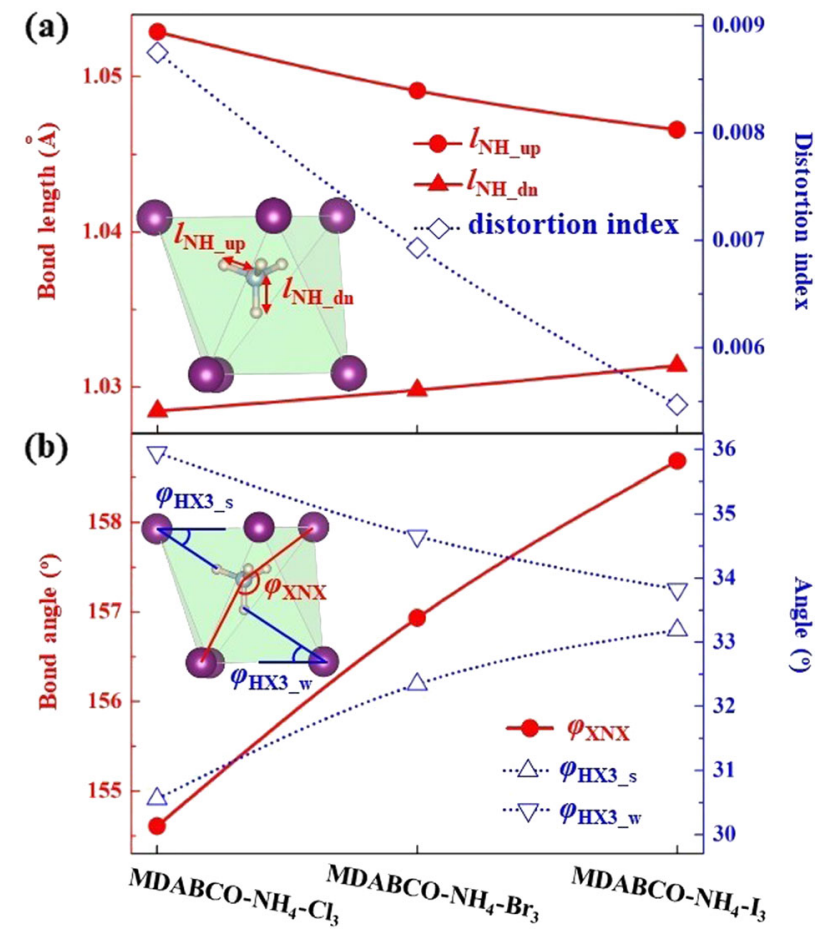

Fig. 4 The structure parameters a of inner $\mathrm{NH}_{4}$ and $\mathbf{b}$ between $\mathrm{NH}_{4}$ and its nearest neighboring $\mathrm{X}$ ions. The solid red symbols refer to the left vertical axis, while the open blue ones refer to the right vertical axis. The inset structures depict the bond lengths and angles

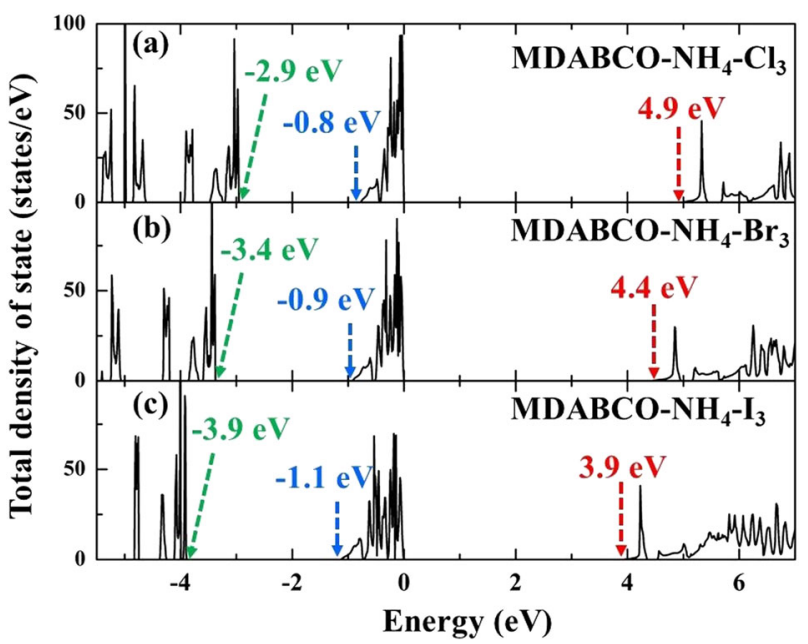

Fig. 5 The calculated electronic density of state of MDABCO-NH $\mathrm{N}_{4}-\mathrm{X}_{3}$. Fermi level is set to zero. Some special points are label with arrows of different color

changes from $30.6^{\circ}$ to $33.2^{\circ}$, increasing $2.6^{\circ}$. With halogen changing from $\mathrm{Cl}$ to $\mathrm{I}$, the evolutions of $\boldsymbol{\varphi}_{\mathrm{HX}{ }_{3} \mathrm{~s}}$ (increasing) and $\boldsymbol{\varphi}_{\mathrm{HX}{ }_{3} \mathrm{w}}$ (decreasing) are opposite to those of $\theta_{\mathrm{HX}{ }_{3} \mathrm{~s}}$ (decreasing)

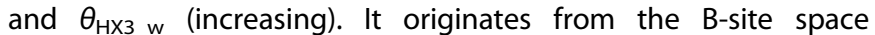
changing of perovskite. With $\mathrm{X}$ ion changing from $\mathrm{I}^{-}$to $\mathrm{Cl}^{-}$(not $\mathrm{Cl}^{-}$to $\mathrm{I}^{-}$), the B-site space of perovskite increases. In MDABCO$\mathrm{NH}_{4}-\mathrm{I}_{3}$, the $\mathrm{NH}_{4}$ group is a little compressed as there is not enough room for it. When it comes to MDABCO- $\mathrm{NH}_{4}-\mathrm{Cl}_{3}$, there is spare room for $\mathrm{NH}_{4}$ group. Because the hydrogen-halogen interaction at the top of Fig. $4 \mathrm{~b}$ inset is stronger than the bottom one, the top hydrogen approaches its neighboring $\mathrm{Cl}$, decreasing $\theta_{\mathrm{HX} \_s}$, while the bottom hydrogen leaves its neighboring $\mathrm{Cl}$, increasing $\theta_{\mathrm{HX} \_w}$. 


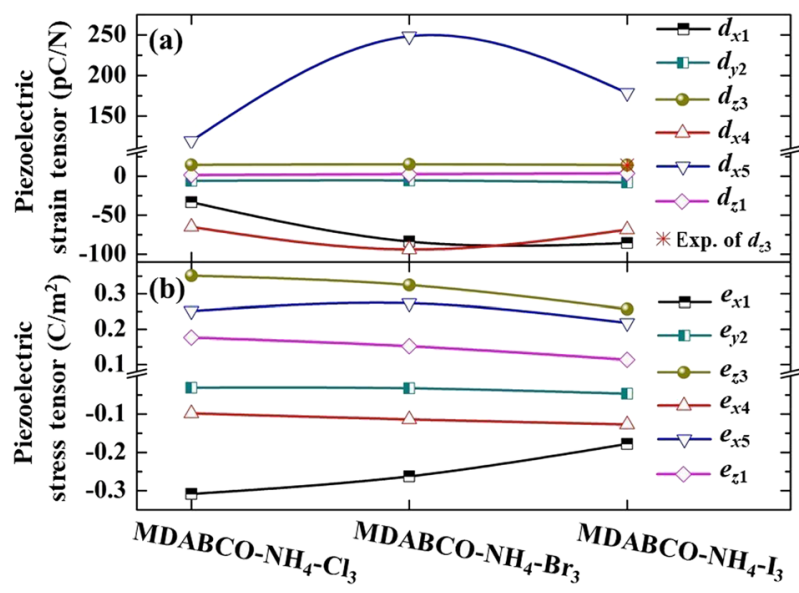

Fig. 6 The calculated piezoelectric strain (a) and stress (b) tensor of MDABCO- $\mathrm{NH}_{4}-\mathrm{X}_{3}$. The experimental measured $d_{z 3}$ of MDABCO-NH $\mathrm{N}_{4}$ $\mathrm{I}_{3}$ is also given

The calculated electronic density of state (DOS) of MDABCO$\mathrm{NH}_{4}-\mathrm{X}_{3}$ are exhibited in Fig. 5. It can be clearly seen that these DOS are divided into three parts. The low energy part (below $-2 \mathrm{eV}$ ) is mainly composed of occupied $\mathrm{N}-2 p, \mathrm{C}-2 p$, and $\mathrm{H}-1 s$ states, the middle energy part (from -2 to $0 \mathrm{eV}$ ) is mainly composed of occupied $\mathrm{Cl}-3 p, \mathrm{Br}-4 p$, and $\mathrm{I}-5 p$ states, and the high energy parts (above $3 \mathrm{eV}$ ) is unoccupied states of $\mathrm{N}, \mathrm{C}, \mathrm{H}$, and halogen. By comparing Fig. $5 \mathrm{a}-\mathrm{c}$, we can see two obvious evolutions with anion changes from $\mathrm{Cl}^{-}$to $\mathrm{I}^{-}$. Firstly, the width of the occupied halogen $p$ orbital increases from $0.8\left(\mathrm{Cl}^{-}\right)$to $1.1\left(\mathrm{I}^{-}\right) \mathrm{eV}$. This width broadening originates from the $\mathrm{X}-\mathrm{N}-\mathrm{X}$ angle changing in Fig. $4 \mathrm{~b}$. With $X$ ion changing from $\mathrm{Cl}^{-}$to $\mathrm{I}^{-}$, the angle of $\mathrm{X}-\mathrm{N}-\mathrm{X}$ angle $\left(\boldsymbol{\varphi}_{\mathrm{XNX}}\right)$ increases toward $180^{\circ}$, resulting into more electron interaction along the $\mathrm{X}-\mathrm{N}-\mathrm{X}$ line. ${ }^{26}$ Secondly, there are obvious gap between the occupied halogen $p$ state and the occupied states of $\mathrm{C}, \mathrm{N}$, and $\mathrm{H}$. This characters indicate the halogen interactions with MDABCO and $\mathrm{NH}_{4}$ are weak. ${ }^{16,27}$ It agrees with the analysis of Figs. 3a and 4a.

Piezoelectric effect allows interconversion between electric field and mechanical deformation. This property is important for applications of sensors, actuators, vibration reducer, and so on. Conventional perovskite ferroelectrics usually require high processing temperatures, ${ }^{18}$ have little mechanical flexibility, and even contain potential toxic elements. ${ }^{4}$ These drawbacks make scientists pay much attention to organic materials. ${ }^{5,9}$ Experiment shows that MDABCO-NH $\mathrm{NH}_{4} \mathrm{I}_{3}$ is an organic piezoelectrics without metal element. The piezoelectric strain coefficient $d_{z 3}$ of MDABCO$\mathrm{NH}_{4}-\mathrm{I}_{3}$ is measure to be $\sim 14 \mathrm{pC} / \mathrm{N}$ at room temperature. ${ }^{9}$ However, other components of piezoelectric tensor are still unknown. Therefore, we calculated the piezoelectric strain and stress tensors of MDABCO- $\mathrm{NH}_{4}-\mathrm{X}_{3}$.

The crystallographic symmetry plays an important role in the piezoelectric phenomena. ${ }^{28}$ According to the definition of the piezoelectric effect, in the matrix notation (with two indices), the piezoelectric strain tensor $d_{\mathrm{ij}}$ of MDABCO- $\mathrm{NH}_{4}-\mathrm{X}_{3}$ (space group $R 3$ ) is

$\left[\begin{array}{cccccc}d_{x 1} & -d_{x 1} & 0 & d_{x 4} & d_{x 5} & -2 d_{y 2} \\ -d_{y 2} & d_{y 2} & 0 & d_{x 5} & -d_{x 4} & -2 d_{x 1} \\ d_{z 1} & d_{z 1} & d_{z 3} & 0 & 0 & 0\end{array}\right]$

The corresponding piezoelectric stress tensor $e_{i j}$ is

$\left[\begin{array}{cccccc}e_{x 1} & -e_{x 1} & 0 & e_{x 4} & e_{x 5} & -e_{y 2} \\ -e_{y 2} & e_{y 2} & 0 & e_{x 5} & -e_{x 4} & -e_{x 1} \\ e_{z 1} & e_{z 1} & e_{z 3} & 0 & 0 & 0\end{array}\right]$
There are six independent coefficients in piezoelectric strain (stress) tensor.

The piezoelectric strain tensor is defined as the ratio of developed strain to the applied electric field. ${ }^{28}$ Our calculated piezoelectric strain tensors are shown in Fig. 6a. The calculated $d_{z 3}$ of $\mathrm{MDABCO}-\mathrm{NH}_{4}-\mathrm{I}_{3}$ is $14.4 \mathrm{pC} / \mathrm{N}$, which agrees very well with the experimental value $\sim 14 \mathrm{pC} / \mathrm{N}^{9}$. This agreement proves the validity of our calculation.

The calculated $d_{x 4}$ and $d_{x 5}$ are much larger than $d_{z 3}$. The largest components of piezoelectric strain tensor for the three crystals are all $d_{x 5}$, which is $119 \mathrm{pC} / \mathrm{N}$ for MDABCO- $\mathrm{NH}_{4}-\mathrm{Cl}_{3}, 248 \mathrm{pC} / \mathrm{N}$ for MDABCO- $\mathrm{NH}_{4}-\mathrm{Br}_{3}$, and $179 \mathrm{pC} / \mathrm{N}$ for MDABCO-NH $\mathrm{H}_{4}-\mathrm{I}_{3}$. They are much larger than the largest component of inorganic crystals, such as lithium niobate $\left(d_{x 5}=68 \mathrm{pC} / \mathrm{N}\right){ }^{29}$ lithium tantalite $\left(d_{x 5}=\right.$ $26 \mathrm{pC} / \mathrm{N}){ }^{29}$ cadmium sulfide $\left(d_{x 5}=-14 \mathrm{pC} / \mathrm{N}\right){ }^{30}$ barium sodium niobate $\left(d_{y 4}=52 \mathrm{pC} / \mathrm{N}\right){ }^{28}$ hexagonal zinc oxide $\left(d_{z 3}=12.4 \mathrm{pC} /\right.$ $\mathrm{N}){ }^{31}$ and hexagonal zinc sulfide $\left(d_{z 3}=3.2 \mathrm{pC} / \mathrm{N}\right) .^{32,33}$ They are even comparable with that of barium titanate $\left(d_{x 5}=242 \mathrm{pC} / \mathrm{N}\right)^{34}$ and are almost one third of that of PZT-5H $\left(d_{x 5}=741 \mathrm{pC} / \mathrm{N}\right) .{ }^{34}$ The above comparison shows that $\mathrm{MDABCO}-\mathrm{NH}_{4}-\mathrm{X}_{3}$ have large piezoelectric responds and are good candidate materials for a variety of piezoelectric applications.

Similarly with piezoelectric strain tensor, piezoelectric stress tensor is defined as the ratio of developed stress to the applied electric field. ${ }^{28}$ Our calculated piezoelectric stress tensors are shown in Fig. $6 \mathrm{~b}$. Except for $e_{\mathrm{x} 1}$ and $e_{\mathrm{z} 3}$, the other components change little with $X$ anion. Furthermore, differently with the condition of $d_{x 5}, e_{x 5}$ is not the largest component of piezoelectric stress tensor. It is well known that the piezoelectric strain tensor $[d]$, piezoelectric stress tensor [e], and elastic compliance tensor [s] satisfy the relation $[d]=[e][s] .^{28}$ This indicates that the large value of $d_{x 5}$ may originates from the large elastic compliance. In the matrix notation (with two indices), the elastic compliance tensor of MDABCO- $\mathrm{NH}_{4}-\mathrm{X}_{3}$ (space group $\mathrm{R3}$ ) is

$\left[\begin{array}{cccccc}s_{11} & s_{12} & s_{13} & s_{14} & -s_{25} & 0 \\ s_{12} & s_{11} & s_{13} & -s_{14} & s_{25} & 0 \\ s_{13} & s_{13} & s_{33} & 0 & 0 & 0 \\ 0 & 0 & 0 & s_{44} & 0 & 2 s_{25} \\ -s_{25} & s_{25} & 0 & 0 & s_{44} & 2 s_{14} \\ 0 & 0 & 0 & 2 s_{25} & 2 s_{14} & 2\left(s_{11}-s_{12}\right)\end{array}\right]$

There are seven independent coefficients in elastic compliance tensor. The calculated values are shown in Fig. 7.

It is clear in Fig. 7 that the $s_{44}$ is the largest component in MDABCO- $\mathrm{NH}_{4}-\mathrm{X}_{3}$. With $\mathrm{X}$ anion changes from $\mathrm{Cl}^{-}$to $\mathrm{I}^{-}$, it firstly

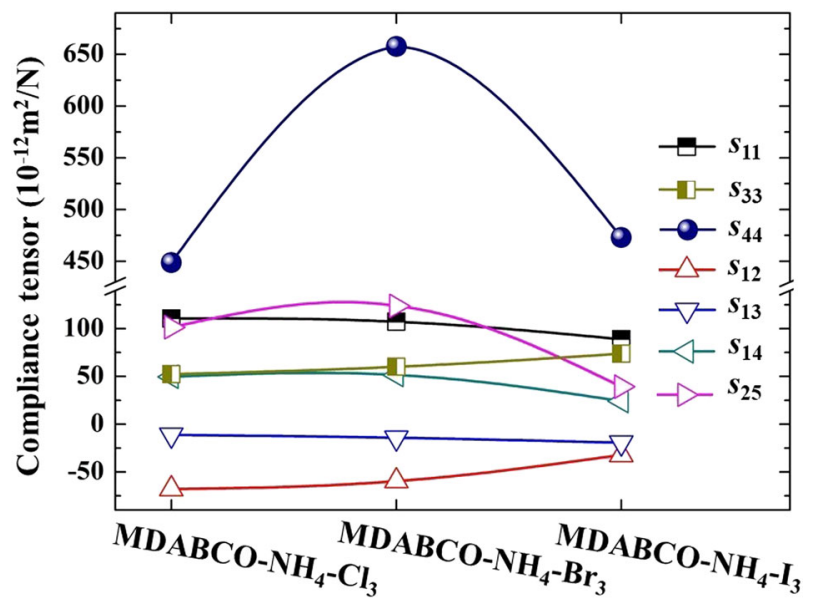

Fig. 7 The calculated elastic compliance tensor of $\mathrm{MDABCO}-\mathrm{NH}_{4}-\mathrm{X}_{3}$, in which $s_{44}$ is the largest component 

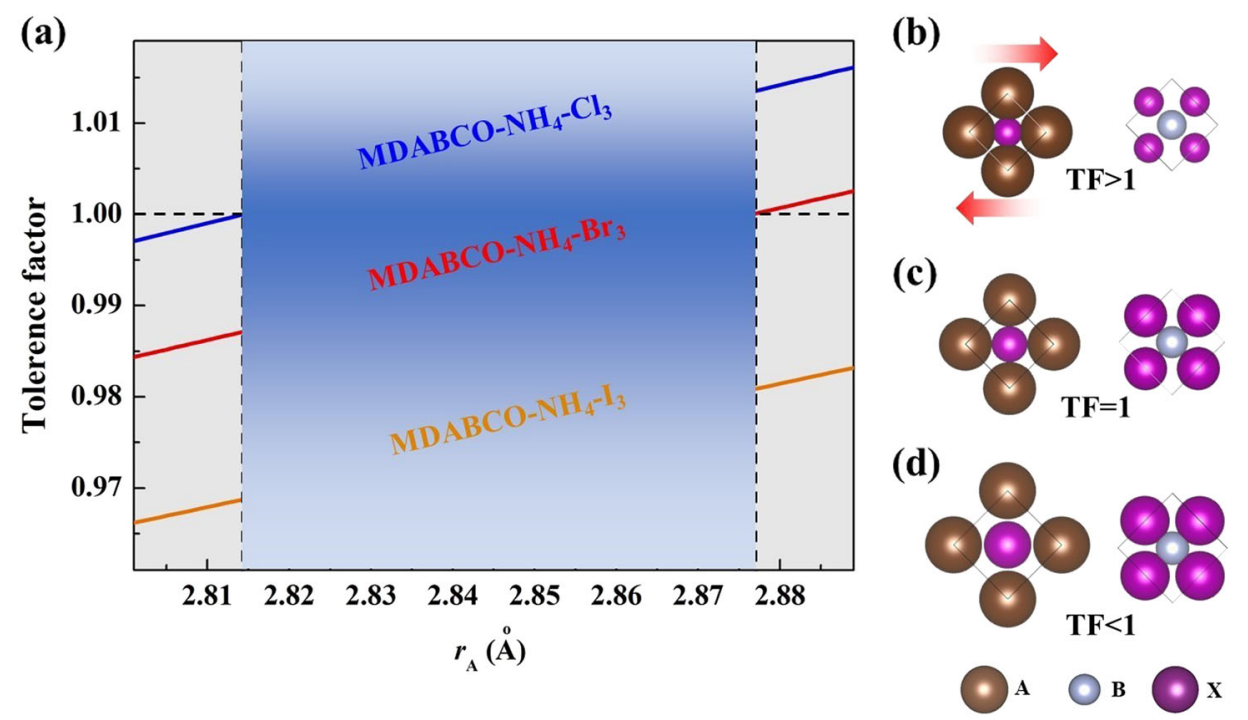

Fig. 8 The tolerance factor MDABCO-NH $\mathrm{N}_{4}-\mathrm{X}_{3}$. a The evolution of tolerance factor with $\mathrm{A}$ ion radius $\left(r_{\mathrm{A}}\right)$. $\mathbf{b}-\mathbf{d}$ The sketches of AX and BX planes for different tolerance factors. The arrows in $\mathbf{b}$ represent shear stress

increases from 449 to 658 and then decreases to $473 \times 10^{-12} \mathrm{~m}^{2} /$ $\mathrm{N}$. This evolution is similar with that of $d_{x 5}$ in Fig. 6a. For MDABCO$\mathrm{NH}_{4}-\mathrm{X}_{3}$, the piezoelectric strain tensor component $d_{x 5}=e_{x 5} \times s_{44}$ $-2 e_{x 1} \times s_{25}-2 e_{y 2} \times s_{14}$. The last term $2 e_{y 2} \times s_{14}$ is about two orders smaller than the first term, and the second term $2 e_{x 1} \times s_{25}$ is about one-third of the first term. Because the $e_{x 5}$ difference for MDABCO-NH4- $X_{3}$ is rather small, the $d_{x 5}$ evolution with halogen is dominated by $S_{44}$.

For MDABCO-NH $H_{4}-\mathrm{X}_{3}, s_{44}$ equals $\left(c_{12}-c_{11}\right) /\left(2 c^{2}{ }_{14}+2 c^{2}{ }_{25}-\right.$ $\left.c_{11} c_{44}+c_{12} c_{44}\right)$, related with five parameters $c_{12}, c_{11}, c_{14}, c_{25}$, and $c_{44}$. No one dominates the others. Therefore, $s_{44}$ is affected by many structure parameters. So as to give an intuitive explanation, we propose a model based on the tolerance factor of perovskite. For an inorganic perovskite $A B X_{3}$, the Goldschmidt tolerance factor (TF) is defined as below ${ }^{35}$

$$
\mathrm{TF}=\frac{r_{\mathrm{A}}+r_{\mathrm{X}}}{\sqrt{2}\left(r_{\mathrm{B}}+r_{\mathrm{X}}\right)}
$$

where $r_{\mathrm{A}}, r_{\mathrm{B}}$, and $r_{\mathrm{X}}$ are the ionic radii of the ions $\mathrm{A}, \mathrm{B}$, and $\mathrm{X}$, respectively. In this model, all ions are assumed to be hard spheres. TF is widely used to analysis the structure of inorganic perovskite. ${ }^{36} \mathrm{TF}=1$ corresponds to an ideal cubic perovskite with $A, B$ and $X$ ions touching each other perfectly. TF $>1$ implies that $A$ cation is too large or $B$ cation too small, while $T F<1$ implies $A$ cation is too small or B cation too large.

This concept is generalized to hybrid perovskites containing organic cations by Kieslich and Becker et al. ${ }^{37-39}$ It is found that the TF value of most hybrid perovskites lies in the range from 0.8 to 1 . Hybrid perovskite structures with $\mathrm{TF}>1$ or $\mathrm{TF}<0.8$ are rarely observed. ${ }^{39}$ So as to get the TF values of MDABCO-NH${ }_{4}-\mathrm{X}_{3}$, ions radii are needed. The Shannon radius of $\mathrm{Cl}^{-}, \mathrm{Br}^{-}$, and $\mathrm{I}^{-}$are 1.81 , 1.96 , and $2.2 \AA$, respectively. ${ }^{40}$ The radius of $\left(\mathrm{NH}_{4}\right)^{+}$is proposed to be $1.46 \AA^{39}$. But the radius of MDABCO is difficult to define because it is not a hard sphere. Based on the available radii of $X$ and $\mathrm{NH}_{4}$, we calculate the TF value evolution with MDABCO radius $\left(r_{\mathrm{A}}\right)$. As shown in Fig. $8 \mathrm{a}$, the TF value of $\mathrm{MDABCO}-\mathrm{NH}_{4}-\mathrm{Cl}_{3}$ is the largest, while that of MDABCO- $\mathrm{NH}_{4}-\mathrm{I}_{3}$ is the smallest. In experiment, MDABCO-NH$-\mathrm{NH}_{4}$ and MDABCO-NH $\mathrm{NH}_{4} \mathrm{I}_{3}$ are successful synthesized, while MDABCO-NH $\mathrm{N}_{4}-\mathrm{Cl}_{3}$ is not. Therefore, it is reasonable to assume that the TF values of MDABCO-NH$-\mathrm{NH}_{4}$ and MDABCO-NH$H_{4}-\mathrm{I}_{3}$ is $<1$, while that of MDABCO-NH$-\mathrm{NH}_{4}-\mathrm{Cl}_{3}$ is $>1$ (the middle light blue region of Fig. 8a). This assumption agrees with the angles analysis of Figs. $3 \mathrm{~b}$ and $4 \mathrm{~b}$. We also give the sketch of AX plane and BX plane for different TF values in Fig. 8b-d. For
Table 2. Calculated elastic stiffness tensor $c_{\mathrm{ij}}$, bulk modulus $B$, shear modulus $G$, and Young's modulus $E$ (GPa) of MDABCO- $\mathrm{NH}_{4}-\mathrm{X}_{3}$

\begin{tabular}{lllllllllll}
\hline Material & $c_{11}$ & $c_{33}$ & $c_{44}$ & $c_{12}$ & $c_{13}$ & $c_{14}$ & $c_{25}$ & $B$ & $G$ & $E$ \\
\hline $\mathrm{MDABCO}_{\mathrm{NH}} \mathrm{N}_{4^{-}}$ & 17.3 & 21.5 & 3.3 & 9.1 & 5.7 & -0.9 & -1.9 & 10.7 & 3.9 & 10.5 \\
$\mathrm{Cl}_{3}$ & & & & & & & & & & \\
${\mathrm{MDABCO}-\mathrm{NH}_{4}-}^{-}$ & 16.7 & 19.4 & 2.3 & 7.8 & 5.8 & -0.7 & -1.7 & 10.2 & 3.3 & 9.0 \\
$\mathrm{Br}_{3}$ & & & & & & & & & & \\
$\mathrm{MDABCO}-\mathrm{NH}_{4^{-}}$ & 15.2 & 16.5 & 2.3 & 6.3 & 5.6 & -0.5 & -0.7 & 9.1 & 3.6 & 9.5 \\
$\mathrm{l}_{3}$ & & & & & & & & & & \\
\hline
\end{tabular}

$\mathrm{TF}>1$, the $\mathrm{A}$ cation is too large, resulting into over compression between $\mathrm{A}$ and $\mathrm{X}$ ions. It is the condition of MDABCO-NH$-\mathrm{NH}_{4}-\mathrm{Cl}_{3}$. For $\mathrm{TF}<1$, the $\mathrm{B}$ cation is too large, resulting into over compression between $B$ and $X$ ions. It is the condition of MDABCO-NH${ }_{4}^{-I_{3}}$. The over compressions of MDABCO- $\mathrm{NH}_{4}-\mathrm{Cl}_{3}$ and MDABCO-NH $\mathrm{H}_{4}-\mathrm{I}_{3}$ increase their shear resistance, reducing their $s_{44}$ values. For MDABCO- $\mathrm{NH}_{4}-\mathrm{Br}_{3}$, its TF value is closer to 1 than that of MDABCO$\mathrm{NH}_{4}-\mathrm{I}_{3}$. It implies there is less over compression between $\mathrm{A}$ and $\mathrm{X}$ ions or $\mathrm{B}$ and $\mathrm{X}$ ions in MDABCO-NH $\mathrm{N}_{4}-\mathrm{Br}_{3}$. Consequently, its shear resistance is less than that of $\mathrm{MDABCO}-\mathrm{NH}_{4}-\mathrm{Cl}_{3}$ and $\mathrm{MDABCO}-\mathrm{NH}_{4}-$ $I_{3}$, resulting in large $s_{44}$ value.

The large elastic compliance tensor in Fig. 7 suggests that MDABCO- $\mathrm{NH}_{4}-\mathrm{X}_{3}$ are soft materials. ${ }^{32}$ So as to investigate their elastic properties, Table 2 gives their bulk and shear moduli with Voigt-Reuss-Hill(VRH) approximation, ${ }^{41}$ which is a good estimation for mechanical properties of polycrystalline materials. ${ }^{16,20,42-44}$ Bulk modulus describes the resistance of a material to a change in volume and shear modulus describes the resistance to a change in shape. Although the crystal structures of $\mathrm{MDABCO}-\mathrm{NH}_{4}-\mathrm{X}_{3}$ are similar with inorganic $\mathrm{ABO}_{3}$ perovskite, their bulk moduli are only around $10 \mathrm{GPa}$. They are much smaller than that of inorganic perovskite $\mathrm{CaTiO}_{3}(170.9 \mathrm{GPa}){ }^{45} \mathrm{BaTiO}_{3}(162 \mathrm{GPa}){ }^{46,47}$ and $\mathrm{PbTiO}^{4}$ $(144 \mathrm{GPa}){ }^{46,47}$ The Young's moduli of MDABCO-NH$-\mathrm{NH}_{4}$ are also around $10 \mathrm{GPa}$, even smaller than that of flexible metal-organic frameworks (MOFs) ${ }^{43}$ : MIL-53(Al) (25.5 GPa), MIL-53(Ga) (19.2 GPa), MIL-47 (25.3 GPa), DMOF-1(lozenge) (11.2 GPa), and DMOF-1 (square) (12.5 GPa).

Bulk modulus is an average value of all directions. Instead, directional Young's modulus characterizes uniaxial stiffness in different directions. As a reference, the directional Young's modulus of rhombohedral $\mathrm{BaTiO}_{3}$ based on the calculated elastic 
(a)

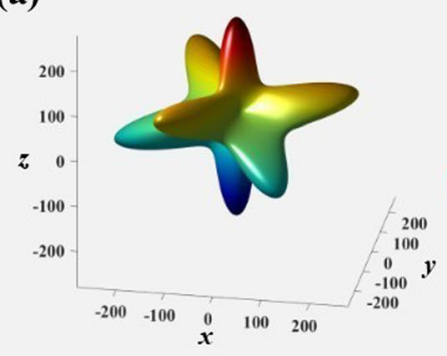

$\mathrm{BaTiO}_{3}$

(c)

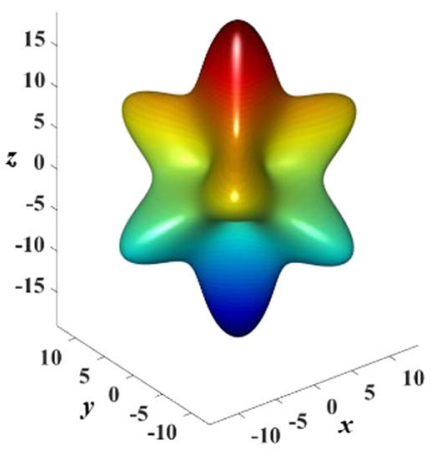

MDABCO-NH4-Cl 3

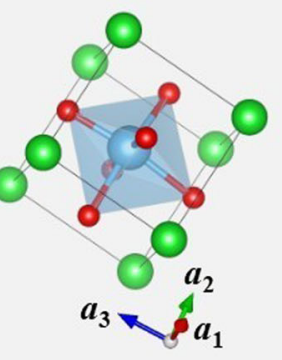

(d)

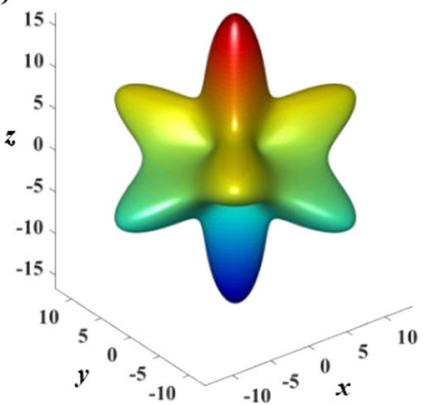

MDABCO-NH4-Br 3 (b)

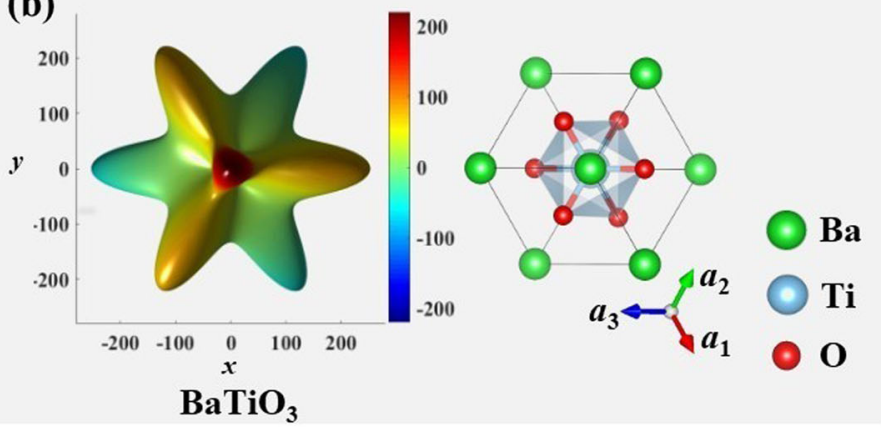

(e)

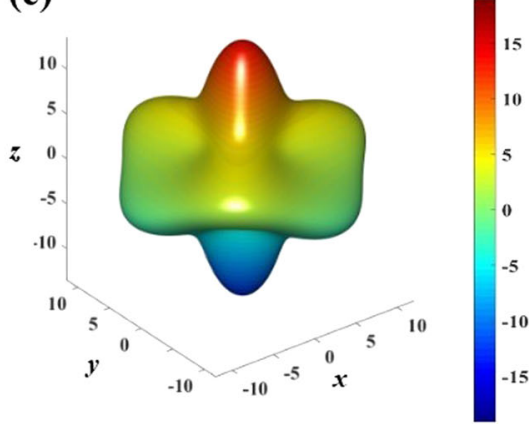

MDABCO-NH4-I

Fig. 9 The calculated directional Young's modulus. $\mathbf{a}, \mathbf{b}$ are directional Young's modulus and crystal structure of $\mathrm{BaTiO}_{3}$ viewed from different directions. c-e are directional Young's modulus of $\mathrm{MDABCO}-\mathrm{NH}_{4}-\mathrm{Cl}_{3}, \mathrm{MDABCO}-\mathrm{NH}_{4}-\mathrm{Br}_{3}$, and $\mathrm{MDABCO}-\mathrm{NH}_{4}-\mathrm{I}_{3}$, respectively. They are represented as three-dimensional (3D) surfaces with axes tick labels in $\mathrm{GPa}$

stiffness using PBE functional ${ }^{48}$ are given in Fig. 9a, b. Similarly with $\mathrm{MDABCO}-\mathrm{NH}_{4}-\mathrm{X}_{3}, \mathrm{BaTiO}_{3}$ takes rhombohedral structure as its lowest energy phase. We set its polar direction along $z$-axis. The crystal structure and directional Young's modulus are shown in the same view point in Fig. 9a. It is clear that the directional Young's modulus has six local minimums and eight high value lobes. The local minimum clearly seen in Fig. $9 a$ is along the $\boldsymbol{a}_{1}$ direction $\left(\boldsymbol{a}_{1}, \boldsymbol{a}_{2}\right.$, and $\boldsymbol{a}_{3}$ are the lattice vectors of the primitive unit cell). The other five local minimums are along $-\boldsymbol{a}_{1}, \pm \boldsymbol{a}_{2}$, and $\pm \boldsymbol{a}_{3}$ directions. They correspond to compression or stretching of $\mathrm{O}-\mathrm{Ti}-\mathrm{O}$ bonds. Owing to the $\mathrm{Ti}$ displacement from the center of oxygen octahedron, these six directions show low rigidity. The directional Young's modulus viewed along the polar direction is shown in Fig. 9b. It is clear that the view direction is perpendicular to the facet of oxygen octahedron. Similarly, the other seven high value lobes are perpendicular to the other seven facets of oxygen octahedron.

Similarly with $\mathrm{BaTiO}_{3}$, the polar direction of $\mathrm{MDABCO}-\mathrm{NH}_{4}-\mathrm{X}_{3}$ is parallel to $z$-axis in Fig. 9c-e. There are six local minimums and eight high-value lobes in the directional Young's modulus of MDABCO- $\mathrm{NH}_{4}-\mathrm{X}_{3}$. These local minimums are along the lattice vectors of their primitive unit cells. They correspond to compression or stretching of $\mathrm{X}-\mathrm{N}-\mathrm{X}$ bonds in octahedrons. The directions of these high value lobes are perpendicular to the facets of $X_{6}$ octahedron. Their directional Young's modulus can be described in the following equation ${ }^{42}$ :

$$
\begin{aligned}
E=1 / & {\left[s_{11} \sin ^{4} \varphi+s_{33} \cos ^{4} \varphi+\left(2 s_{13}+s_{44}\right) \sin ^{2} \varphi \cos ^{2} \varphi\right.} \\
& \left.+2\left(s_{14} \sin 3 \theta-s_{25} \cos 3 \theta\right) \cos \varphi \sin ^{3} \varphi\right]
\end{aligned}
$$

where $\theta$ is the azimuthal angle in the $x y$ plane from the $x$-axis $(0 \leq$ $\theta<2 \pi)$, and $\varphi$ is the zenith angle from the positive $z$ axis $(0 \leq \varphi \leq$ $\pi)$. It can be derived from Eq. (3) that $E$ equals $1 / s_{33}$ with $\varphi=0$. The $s_{33}$ value of MDABCO-NH $\mathrm{N}_{4}-\mathrm{X}_{3}(\mathrm{X}=\mathrm{Cl}, \mathrm{Br}, \mathrm{I})$ is $52.3,60.1$, and $73.9 \times$ $10^{-12} \mathrm{~m}^{2} / \mathrm{N}$, respectively. Correspondingly, the highest value of the top lobe in Fig. 9c-e is 19.1, 16.6, and 13.5 GPa, respectively. When it comes to $x y$ plane, $\varphi=\pi / 2$ and $E=1 / s_{11}$. Therefore, $E$ value in the $x y$ plane has no relationship with $\theta$ and becomes a circle with radius $1 / s_{11}$. The $s_{11}$ value of $\mathrm{MDABCO}-\mathrm{NH}_{4}-\mathrm{X}_{3}(\mathrm{X}=\mathrm{Cl}, \mathrm{Br}, \mathrm{I})$ is $110.8,107.3$, and $88.9 \times 10^{-12} \mathrm{~m}^{2} / \mathrm{N}$, respectively. Their corresponding circle radii in the $x y$ plane are $9.0,9.3$, and $11.2 \mathrm{GPa}$. In Eq. (3), the only term related with angle $\theta$ is $\left(s_{14} \sin 3 \theta-s_{25} \cos 3 \theta\right)$, which means $z$-axis is a threefold axis. The maximum and minimum values of this term are $\sqrt{\left(s_{14}^{2}+s_{25}^{2}\right)}$ and $-\sqrt{\left(s_{14}^{2}+s_{25}^{2}\right)}$, respectively. Therefore, the anisotropy with angle $\theta$ is only related with $g=\sqrt{\left(s_{14}^{2}+s_{25}^{2}\right)}$. The $g$ value of MDABCO$\mathrm{NH}_{4}-\mathrm{X}_{3}(\mathrm{X}=\mathrm{Cl}, \mathrm{Br}, \mathrm{I})$ is $112.9,134.1$, and $46.1 \times 10^{-12} \mathrm{~m}^{2} / \mathrm{N}$, respectively. MDABCO-NH value of MDABCO- $\mathrm{NH}_{4}-\mathrm{I}_{3}$ is much lower than the others. That is why Fig. 9e looks much smoother than Fig. 9c, d.

In summary, we calculated the structure, electronic density of state, piezoelectric response, and elastic properties of metal-free organic perovskite MDABCO-NH$H_{4}-\mathrm{X}_{3}$. The MDABCO and $\mathrm{NH}_{4}$ groups performs like a rigid body in MDABCO-NH$-\mathrm{N}_{4}$, and they are linked to the $\mathrm{I}_{6}$ octahedron network by $\mathrm{H}-\mathrm{X}$ interaction. The high ferroelectric Curie temperature is closely related with the break of this $\mathrm{H}-\mathrm{X}$ interaction. With halogen changing from $\mathrm{Cl}$ to $\mathrm{I}$, the tolerance factor of MDABCO- $\mathrm{NH}_{4}-\mathrm{X}_{3}$ increases from lower than 1 to higher than 1. Based on Born effective charges, the calculated dipole moments of the MDABCO and $\mathrm{NH}_{4}$ groups are negligible. Therefore, the large spontaneous polarization of MDABCO-NH${ }_{4}-\mathrm{I}_{3}$ mainly results from the off-centers of $\mathrm{MDABCO}$ and $\mathrm{NH}_{4}$ relative to $\mathrm{X}$ ions. Our calculated piezoelectric strain component $d_{z 3}(14.4 \mathrm{pC} /$ $\mathrm{N})$ of $\mathrm{MDABCO}-\mathrm{NH}_{4}-\mathrm{I}_{3}$ agrees very well with experimental value $(\sim 14 \mathrm{pC} / \mathrm{N})$. Although most organic materials have a very weak piezoelectric response, we found that some piezoelectric strain components of MDABCO-NH $\mathrm{N}_{4}-\mathrm{X}_{3}$ have large values. Among the six independent components, the largest one is $d_{x 5}$. It is $119 \mathrm{pC} / \mathrm{N}$ for MDABCO- $\mathrm{NH}_{4}-\mathrm{Cl}_{3}, 248 \mathrm{pC} / \mathrm{N}$ for MDABCO- $\mathrm{NH}_{4}-\mathrm{Br}_{3}$, and $179 \mathrm{pC} / \mathrm{N}$ for MDABCO-NH $-\mathrm{NH}_{4}$. The large value of $d_{x 5}$ is closely related with the large value of $s_{44}$. This means that the large piezoelectric strain 
response of $\mathrm{MDABCO}-\mathrm{NH}_{4}-\mathrm{X}_{3}$ is mainly originated from their softness. These unique properties of $\mathrm{MDABCO}-\mathrm{NH}_{4}-\mathrm{X}_{3}$ make them good candidates as soft, low-density and bio-friendly piezoelectrics for various important applications, such as flexible devices, implantable systems, and micro robots.

\section{METHODS}

we performed the density-functional calculation using $\mathrm{PBE}^{10}$ and $\mathrm{PBE}-\mathrm{D} 3^{11}$ methods as implemented in the Vienna ab initio simulation package (VASP). ${ }^{12-14}$ The projector-augmented wave method was used to represent the electron-ion interaction. ${ }^{49}$ The valence-electron configurations were $2 s^{2} 2 p^{2}$ for $C, 2 s^{2} 2 p^{3}$ for $\mathrm{N}$, and $n s^{2} n p^{5}$ for halogen. The wave function was expanded in a plane-wave basis set with an energy cutoff of $650 \mathrm{eV}$ and the first Brillouin zone of primitive unit cell was sampled on a $3 \times 3 \times 3$ mesh. The lattice parameters and atomic positions were fully relaxed until stress and forces were $<0.05 \mathrm{GPa}$ and $10 \mathrm{meV} / \mathrm{A}$, respectively. The elastic stiffness is calculated with finite difference method. ${ }^{50}$ It applies six finite strains (three normal and three shearing strains) to an optimized structure. All these six deformations correspond to strains of \pm 0.015 , so as to keep strains in the elastic region. Then, the corresponding stress are calculated and the elastic stiffness constants are obtained by the strain-stress relationship. After that, the elastic compliance is obtained by inverting the elastic stiffness matrix directly. The piezoelectric constants, Born effective charges and zone center phonon frequencies are calculated by VASP package using density-functional perturbation theory. ${ }^{51}$ In order to obtain these values, three kinds of perturbations are applied to a crystal. They are atomic displacement away from equilibrium position $u_{i}$, strain $S_{j}$ and electric field $E_{k}$. The corresponding responses to these three perturbations are force $F_{l}$, stress $T_{m}$, and polarization $P_{n}$. Based on these perturbations and their responses, one can obtain force-constant matrix $\mathrm{d} F_{/} / \mathrm{d} u_{i}$, Born effective charge $\mathrm{d} P_{n} / \mathrm{d} u_{i}$ and piezoelectric response $\mathrm{d} P_{n} / \mathrm{d} S_{j}$.

\section{DATA AVAILABILITY}

The data that support the findings of this study are available from the corresponding author (Hui Wang) upon reasonable request.

\section{ACKNOWLEDGEMENTS}

This work is supported by the National Natural Science Foundation of China (U1404111, 11504089, 61874160, 61675064, and 11404098), Young Key Teacher of Henan Province (2016GGJS-059) and Collaborative Innovation Center of Nonferrous Metals of Henan Province. The crystal structure was drawn using the VESTA software. $^{52}$

\section{AUTHOR CONTRIBUTIONS}

H.W., H.H.L., Z.Y.Z., and Z.H.L. did the PBE calculations, Z.L.L., T.W.L., and H.H. did the $\mathrm{PBE}+\mathrm{D} 3$ calculations. W.W.J., H.S.L., and X.W.C. provided valuable comments and suggestions to the work. H.W. and H.H. wrote the paper. All authors have given approval to the final version of the manuscript.

\section{ADDITIONAL INFORMATION}

Competing interests: The authors declare no competing interests.

Publisher's note: Springer Nature remains neutral with regard to jurisdictional claims in published maps and institutional affiliations.

\section{REFERENCES}

1. Bhalla, A. S., Guo, R. \& Roy, R. The perovskite structure-a review of its role in ceramic science and technology. Mater. Res. Innov. 4, 3-26 (2016).

2. Niu, G., Guo, X. \& Wang, L. Review of recent progress in chemical stability of perovskite solar cells. J. Mater. Chem. A 3, 8970-8980 (2015).

3. Bednorz, J. G. \& Müller, K. A. Perovskite-type oxides-The new approach to highTcsuperconductivity. Rev. Mod. Phys. 60, 585-600 (1988).

4. Zhang, L. et al. Giant polarization in super-tetragonal thin films through interphase strain. Science 361, 494-497 (2018).

5. You, Y. -M. et al. An organic-inorganic perovskite ferroelectric with large piezoelectric response. Science 357, 306-309 (2017).
6. Akutagawa, T. et al. Ferroelectricity and polarity control in solid-state flip-flop supramolecular rotators. Nat. Mater. 8, 342 (2009).

7. Zhang, Y. et al. Ferroelectricity induced by ordering of twisting motion in a molecular rotor. J. Am. Chem. Soc. 134, 11044-11049 (2012).

8. Xu, B. \& Ren, S. Integrated charge transfer in organic ferroelectrics for flexible multisensing materials. Small 12, 4502-4507 (2016).

9. Ye, H. -Y. et al. Metal-free three-dimensional perovskite ferroelectrics. Science $\mathbf{3 6 1}$, 151-155 (2018).

10. Perdew, J. P., Burke, K. \& Ernzerhof, M. Generalized gradient approximation made simple. Phys. Rev. Lett. 77, 3865-3868 (1996).

11. Grimme, S., Antony, J., Ehrlich, S. \& Krieg, H. A consistent and accurate ab initio parametrization of density functional dispersion correction (DFT-D) for the 94 elements H-Pu. J. Chem. Phys. 132, 154104 (2010).

12. Kresse, G. \& Furthmüller, J. Efficient iterative schemes for ab initio total-energy calculations using a plane-wave basis set. Phys. Rev. B 54, 11169-11186 (1996).

13. Kresse, G. \& Furthmüller, J. Efficiency of ab-initio total energy calculations for metals and semiconductors using a plane-wave basis set. Comput. Mater. Sci. 6, 15-50 (1996).

14. Kresse, G. \& Hafner, J. Ab initio molecular dynamics for liquid metals. Phys. Rev. $B$ 47, 558-561 (1993).

15. Gong, X. et al. First-principles investigation of the Raman spectroscopy of perovskite-like crystal K3B6O10Cl. Comput. Mater. Sci. 83, 86-91 (2014).

16. Han, H., Yin, G. \& Wickramaratne, D. A first-principles investigation of the electronic, elastic, piezoelectric and acoustic properties of $\mathrm{K} 3 \mathrm{~B} 6 \mathrm{O} 10 \mathrm{Cl}$. Comput. Mater. Sci. 69, 81-86 (2013).

17. Wang, $\mathrm{H}$. et al. Pressure induced variation of second harmonic efficiency of K3B6O10Cl. Appl. Phys. Lett. 103, 101902 (2013).

18. Sakai, $\mathrm{H}$. et al. Displacement-type ferroelectricity with off-center magnetic ions in perovskite Sr_\{1-x\}Ba_\{x\}MnO_\{3\}. Phys. Rev. Lett. 107, 137601 (2011).

19. Giovannetti, G., Kumar, S., Ortix, C., Capone, M. \& van den Brink, J. Microscopic origin of large negative magnetoelectric coupling in $\mathrm{Sr}\left\{\{1 / 2\} \mathrm{Ba} \_\{1 / 2\} \mathrm{MnO} \_\{3\}\right.$. Phys. Rev. Lett. 109, 107601 (2012).

20. Z-j, Wu et al. Structures and elastic properties of superhard IrN2 and IrN3 from first principles. Phys. Rev. B 76, 054115 (2007).

21. Chakarova-Käck, S. D., Schröder, E., Lundqvist, B. I. \& Langreth, D. C. Application of van der Waals density functional to an extended system: Adsorption of benzene and naphthalene on graphite. Phys. Rev. Lett. 96, 146107 (2006).

22. Silvestrelli, P. L. Improvement in hydrogen bond description using van der Waalscorrected DFT: The case of small water clusters. Chem. Phys. Lett. 475, 285-288 (2009).

23. Dion, M., Rydberg, H., Schröder, E., Langreth, D. C. \& Lundqvist, B. I. Van der Waals density functional for general geometries. Phys. Rev. Lett. 92, 246401 (2004).

24. Kolb, B. \& Thonhauser, T. van der Waals density functional study of energetic, structural, and vibrational properties of small water clusters and ice I h. Phys. Rev. B 84, 045116 (2011).

25. Baur, W. H. The geometry of polyhedral distortions. Predictive relationships for the phosphate group. Acta Crystallogr Sect. B: Struct. Sci. 30, 1195-1215 (1974).

26. He, J., Borisevich, A., Kalinin, S., Pennycook, S. \& Pantelides, S. Control of octahedral tilts and magnetic properties of perovskite oxide heterostructures by substrate symmetry. Phys. Rev. Lett. 105, 227203 (2010).

27. Fuentes-Cabrera, M., Nicholson, D. M., Sumpter, B. G. \& Widom, M. Electronic structure and properties of isoreticular metal-organic frameworks: The case of MIRMOF1 ( $M=$ Zn, Cd, Be, Mg, and Ca). J. Chem. Phys. 123, 124713 (2005).

28. Auld, B. A. Acoustic Fields and Waves in Solids (Wiley, 1973), Vol. I, Chap. 8.

29. Yue, W. \& Yi-Jian, J. Crystal orientation dependence of piezoelectric properties in LiNbO3 and LiTaO3. Opt. Mater. 23, 403-408 (2003).

30. Bowen, C., Kim, H., Weaver, P. \& Dunn, S. Piezoelectric and ferroelectric materials and structures for energy harvesting applications. Energy Environ. Sci. 7, 25-44 (2014).

31. Crisler, D., Cupal, J. \& Moore, A. Dielectric, piezoelectric, and electromechanical coupling constants of zinc oxide crystals. Proc. IEEE 56, 225-226 (1968).

32. Tokarev, E., Kobyakov, I., Kuz'mina, I., Lobachev, A. \& Pado, G. Elastic, dielectric, and piezoelectric properties of zincite in the $4.2-800 \mathrm{~K}$ temperature range. Sov. Phys. Solid State 17, 629-632 (1975).

33. Catti, M., Noel, Y. \& Dovesi, R. Full piezoelectric tensors of wurtzite and zinc blende $\mathrm{ZnO}$ and ZnS by first-principles calculations. J. Phys. Chem. Solids 64, 2183-2190 (2003).

34. Hayward, G., Bennett, J. \& Hamilton, R. A theoretical study on the influence of some constituent material properties on the behavior of 1-3 connectivity composite transducers. J. Acoust. Soc. Am. 98, 2187-2196 (1995).

35. Goldschmidt, V. M. Die gesetze der krystallochemie. Naturwissenschaften 14, 477-485 (1926).

36. Reaney, I. M., Colla, E. L. \& Setter, N. Dielectric and structural characteristics of Baand Sr-based complex perovskites as a function of tolerance factor. Jpn. J. Appl. Phys. 33, 3984 (1994). 
37. Burger, S., Ehrenreich, M. \& Kieslich, G. Tolerance factors of hybrid organic-inorganic perovskites: recent improvements and current state of research. J. Mater. Chem. A 6, 21785-21793 (2018).

38. Travis, W., Glover, E., Bronstein, H., Scanlon, D. \& Palgrave, R. On the application of the tolerance factor to inorganic and hybrid halide perovskites: a revised system. Chem. Sci. 7, 4548-4556 (2016).

39. Kieslich, G., Sun, S. \& Cheetham, A. K. Solid-state principles applied to organic-inorganic perovskites: new tricks for an old dog. Chem. Sci. 5, 4712-4715 (2014).

40. Shannon, R.D. Revised effective ionic radii and systematic studies of interatomie distances in halides and chaleogenides. Acta Crystallogr. Sect. A 32, 751-767 (1976).

41. Hill, R. The elastic behaviour of a crystalline aggregate. Proc. Phys. Soc. Sect. A 65 349 (1952).

42. Yu, C. -F., Cheng, H. -C. \& Chen, W. -H. An Ab-initio study of structural, elastic electronic and thermodynamic properties of triclinic Cu 7 In 3. Mater. Chem. Phys. 174, 70-80 (2016).

43. Ortiz, A. U., Boutin, A., Fuchs, A. H. \& Coudert, F. X. Anisotropic elastic properties of flexible metal-organic frameworks: how soft are soft porous crystals? Phys. Rev. Lett. 109, 195502 (2012).

44. Oganov, A. R. Computer Simulation Studies of Minerals. Ph.D. Thesis, University of London (2002).

45. Ross, N. L. \& Angel, R. J. Compression of $\mathrm{CaTiO} 3$ and $\mathrm{CaGeO} 3$ perovskites. Am Mineral. 84, 277-281 (1999).

46. Li, Z., Grimsditch, M., Foster, C. \& Chan, S. -K. Dielectric and elastic properties of ferroelectric materials at elevated temperature. J. Phys. Chem. Solids 57, 1433-1438 (1996).

47. Piskunov, S., Heifets, E., Eglitis, R. \& Borstel, G. Bulk properties and electronic structure of SrTiO3, $\mathrm{BaTiO} 3, \mathrm{PbTiO} 3$ perovskites: an ab initio HF/DFT study. Comput. Mater. Sci. 29, 165-178 (2004).
48. Mahmoud, A., Erba, A., El-Kelany, K. E., Rérat, M. \& Orlando, R. Low-temperature phase of BaTiO 3: Piezoelectric, dielectric, elastic, and photoelastic properties from ab initio simulations. Phys. Rev. B 89, 045103 (2014).

49. Blöchl, P. E. Projector augmented-wave method. Phys. Rev. B 50, 17953-17979 (1994).

50. Le Page, Y. \& Saxe, P. Symmetry-general least-squares extraction of elastic data for strained materials from ab initio calculations of stress. Phys. Rev. B 65, 104104 (2002).

51. Wu, X., Vanderbilt, D. \& Hamann, D. Systematic treatment of displacements, strains, and electric fields in density-functional perturbation theory. Phys. Rev. $B$ 72, 035105 (2005).

52. Momma, K. \& Izumi, F. VESTA 3for three-dimensional visualization of crystal, volumetric and morphology data. J. Appl. Crystallogr 44, 1272-1276 (2011).

(i) Open Access This article is licensed under a Creative Commons By Attribution 4.0 International License, which permits use, sharing, adaptation, distribution and reproduction in any medium or format, as long as you give appropriate credit to the original author(s) and the source, provide a link to the Creative Commons license, and indicate if changes were made. The images or other third party material in this article are included in the article's Creative Commons license, unless indicated otherwise in a credit line to the material. If material is not included in the article's Creative Commons license and your intended use is not permitted by statutory regulation or exceeds the permitted use, you will need to obtain permission directly from the copyright holder. To view a copy of this license, visit http://creativecommons. org/licenses/by/4.0/.

(c) The Author(s) 2019 